\title{
Forecasting of Warranty Returns Based on the Reliability of Delivery Assessment
}

\author{
Teresa GAJEWSKA*, Grzegorz KACZOR, Maciej SZKODA
}

\begin{abstract}
The paper presents a method to evaluate the reliability of deliveries with the application of Reliasoft Weibull++ software. The first stage in the proposed method was to collect data on outbound deliveries on a monthly basis and convert them into reliability data (life data). Next, by combining selected statistical tests and the maximum likelihood estimation method, the most accurate model of reliability of deliveries was obtained. Using the model which was generated, selected reliability indices were determined, such as: reliability of deliveries, unreliability of deliveries, failure rate of deliveries. Consequently, the number of future failed deliveries was forecast, taking into account the confidence bounds. The approach presented may be easily applied in companies in the logistics sector. The authors underlined that the reliability of deliveries is one of the key factors determining business competitiveness.
\end{abstract}

Keywords: Nevada Chart; reliability of deliveries; warranty analysis; Weibull distribution

\section{INTRODUCTION}

Assessment of the reliability of deliveries in logistic services is one of the most important issues that refer to the quality level of logistic systems. It plays a significant role in forecasting the number of returned deliveries.

In general, reliability is the probability that a component or a system will perform the required function for a given period of time when used under pre-determined operating conditions [11]. Reliability plays an important role in logistics services, shaping many delivery-related parameters. These include, first and foremost: punctuality, completeness and accuracy of deliveries. The concept of reliability in logistics means that all work related to the delivery will be carried out without any interference. The goal of such actions is to keep the warranty returns as low as possible. This may be done thanks to the provision of adequate technical facilities as well as accurate preparation of documentation related to deliveries. The term reliability of deliveries also means informing the customer about the current delivery status and providing relevant information in the event of the impossibility of delivering the goods or providing the service within a predetermined period. [4, 9 , $10,26]$.

Reliability involves almost all aspects related to the characteristics of deliveries, from cost management, customer satisfaction, proper management of resources, through the ability to sell products or services, to safety and product quality [17]. Reliability analysis as the one of the factors determining the customer's satisfaction level was the topic of scientific research projects pursued by the many authors. For example, Meng Lian, Lin and Chen analysed inter alia: the Quick Response Systems, complete customer service, integration of system inventory, on-time delivery and service safety [12].

Nowadays, there is a need to increase the reliability of deliveries in the area of logistic services. New methods require to be developed or existing ones should be improved to assess reliability. Of particular importance is the schematic approach in which deliveries are presented as an organized set of elements related to the transportation process. The reliability analysis provides a schematic approach which plays a significant role in assessing the number of returns. It allows preventive measures to be taken in order to improve the efficiency of deliveries.
Based on a detailed analysis of selected scientific papers, the authors consider the following research to be the right approach.

\section{LITERATURE REVIEW}

According to one of the concepts, the reliability of deliveries is understood to mean the ability of the system to carry out, in an undisturbed fashion, the process of delivering the required logistic resources (spare parts, crew, equipment, etc.) to the technical system. One definition of reliability of deliveries states that it is a feature that determines the degree of satisfaction of customer needs throughout the entire supply chain, whose functioning cannot be disturbed by the appearance of any failure. This is clearly related to achieving the requirements set by the customer, $[2,7]$.

Despite the existence of many definitions of reliability of supply in logistics, this concept has still not been fully explained to date. It is often equated with probabilistic and deterministic approaches. The deterministic feature includes the fulfilment or failure to fulfil the particular criteria, whereas the probabilistic approach uses mathematical models to describe random phenomena that affect supply disruptions. This is also associated with the concept of availability, which determines the share of these disturbances during the delivery process. It is important in mathematical modelling to determine the duration of the delivery and to determine the conditions for its implementation. This affects the maintainability of delivery. This is the property regarding the provision and maintenance of delivery conditions at the highest level. It includes both crews and services, which should be supported by additional external technical measures. [13, $16,20]$.

In order to demonstrate the high importance of reliability of deliveries in terms of competitiveness of logistics services, a survey was conducted. Quantitative research was carried out in accordance with literature recommendations. A specially prepared questionnaire was sent to both service providers and recipients. The results of the survey were to give a picture of the difference in the perception of goals by these two groups. The survey concerned 46 enterprises that provided their services in the area of refrigerated transport and 269 recipient enterprises. 
Two-phase studies were performed in 2010 and 2012. The vast majority of service providers $(70 \%)$ as well as a significant part of recipients $(40 \%)$ unanimously recognized reliability as an important key determining the competitiveness of a company. [14, 18].

The presented preliminary results testify to the importance of reliability of deliveries for the company's competitiveness. Therefore, it seems reasonable to develop methods to determine the amount of warranty returns. As a result, it will be possible to develop preventive strategies for companies that will improve their efficiency. Commonly used methods for forecasting and returning unfit goods and services are based on historical data from internal enterprise databases. [8].

In recent years, there has been a noticeable increase in the importance of quality of supply, which consists of reliability and security. This is evidenced by the topics discussed as part of the publication [3, 19]. Researchers propose new methods for analysing warranty returns. A good example is the automotive industry, where there is a problem of providing the required number of spare parts in response to customer complaints. Often in the analyses related to warranty returns the problem of costs is raised.

In selected works, historical data and data resulting from the specificity of the analysis object are used. For motor vehicles, their age, use and maintenance data may be taken into account. The proposed methods usually have a number of advantages, but they are also not without restrictions. Most often, these limitations are complicated mathematical equations that are difficult to use in practice. Classic reliability analyses are proposed, which are often supported by the use of specialized computer tools [1, 23].

Some papers deal with the problem of warranty analysis when incomplete returns data are only available. The example is the work [5], in which the authors used a two-dimensional model, and also developed a diagnostic tool for obtaining information on irregularities in deliveries and changes in the function of failure rate function [5]. On the other hand, Tsoukalas \& Agrafiotis Agrafiotis took into account the age and use of a non-renewable object in his work. The impact of replacement costs for failed components was also analysed. [21]. Huang et. all developed a two-dimensional warranty policy for a repairable product, taking into account the product's lifetime and usage. The proposed model uses Weibull distribution to model the breakdown process [6]. In turn, the authors of paper [22] proposed a new approach to reliability improvement by reducing the costs of warranty claims servicing. To show the applicability of the proposed solution, a numerical example was used.

Fig. 1 presents the results of research regarding the importance of reliability deliveries as one of the most important factors determining the level of competitiveness of a company operating in the field of refrigerated transport. In the opinion of about $70 \%$ of the representatives of service providers and over $40 \%$ of the representatives of customers, the reliability of deliveries is in the particular importance for determining the level of the company's competitiveness [2].

Sometimes, the sales process becomes uncertain due to its intermittence. Hence, it is difficult to predict the warranty demand. To solve this inconvenience, the authors developed a forecasting technique to estimate the warranty demands for time-varying sales processes [25]. The uncertainty existing in the process of optimization of the warranty policies was also the topic of paper [24]. The authors discussed the issue concerned with the optimization of warranty policies. They applied a real-world example to underline the application of the novel method.

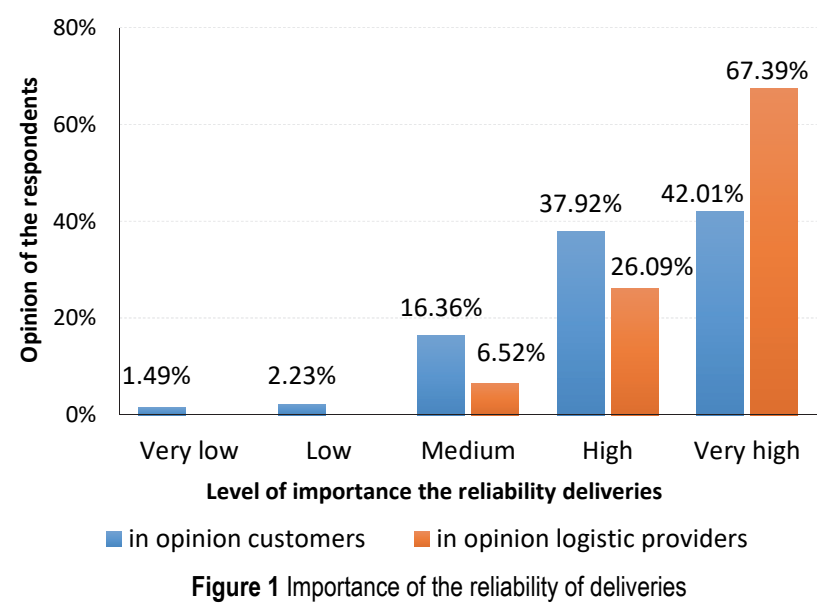

\section{METHODOLOGY}

This chapter includes a case study of a reliability assessment of outbound deliveries. We assume that a company delivers its products to customers. Failures occur in normal operation of the products, and a warranty claim may appear. The company records the information about the volume of sales and returns.

The first stage in the proposed method is to collect data on outbound deliveries, on a monthly basis, and convert them into reliability data (life data). In order to check the period in which failed outbound deliveries were returned, the Nevada Chart format from ReliaSoft Weibull++ software was used (Fig. 2).

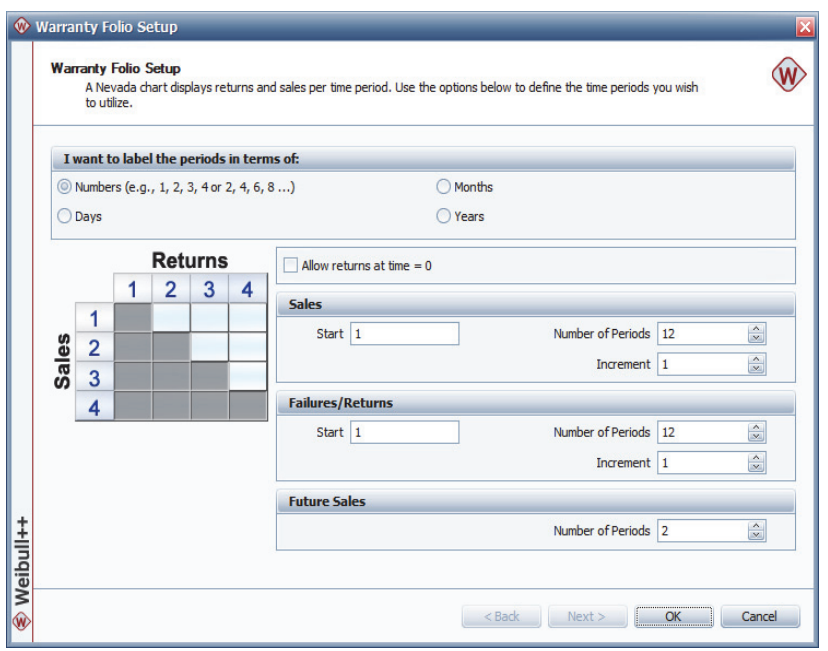

Figure 2 Application of Weibull++ software to assess the reliability of deliveries

Next, based on the methodology of warranty analysis (subsection 3.2), these data were transformed into life data (Fig. 3). Then, a classical reliability analysis was conducted to consist in the fitting a mathematical model to the empirical data and estimating its parameters. We thus obtained the reliability characteristics showing the change 
in the probability of occurrence of returns and could predict the amount of returns over a specific period of time.

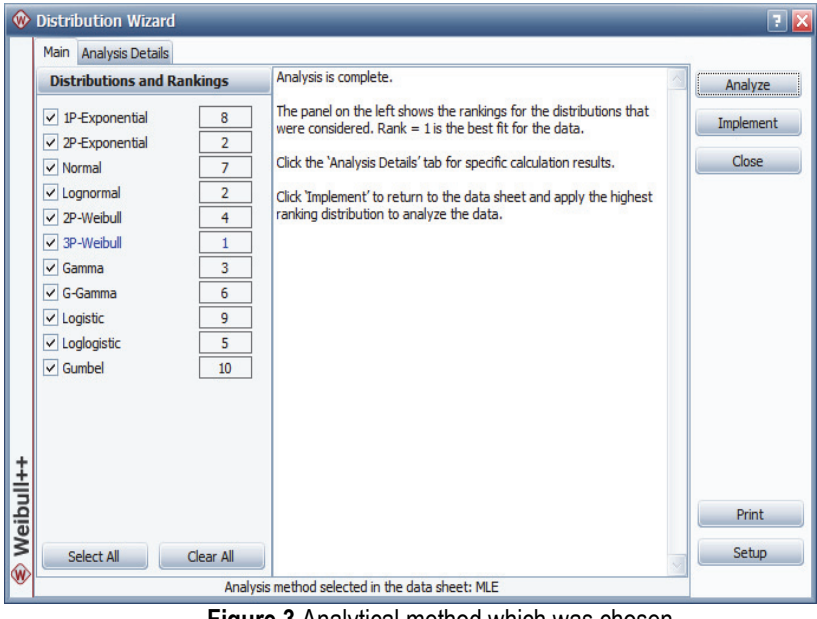

Figure 3 Analytical method which was chosen

Reliability of deliveries is understood as the meeting of the following criteria: timeliness, completeness and faultlessness of deliveries. Failure to meet one of these criteria will result in a complaint to the supplier who bears the consequences thereof.

It is worth mentioning that the object of our analysis was not the logistic company. We focused on the supply system.

\subsection{Data for Analysis}

In order to analyse the reliability of deliveries we used a set of data containing the information about the deliveries placed on the market (Tab. 1).

The chart includes the failed deliveries as a result of the failure to meet the specific criteria presented in the previous section, as well as the deliveries that were successfully realised. Therefore, a given number of returns $(F)$ and suspensions $(S)$ is related to a certain in-service quantity. This information may be converted into the simple time to failure set and used for a further reliability analysis by the use of the popular techniques [27].

The company recorded the following data set about deliveries:

Table 1 Deliveries to be provided

\begin{tabular}{|c|c|}
\hline In-service quantity & Month \\
\hline 130 & 1 \\
\hline 142 & 2 \\
\hline 112 & 3 \\
\hline 125 & 4 \\
\hline 120 & 5 \\
\hline 105 & 6 \\
\hline 123 & 7 \\
\hline 118 & 8 \\
\hline 135 & 9 \\
\hline 125 & 10 \\
\hline 102 & 11 \\
\hline 110 & 12 \\
\hline
\end{tabular}

Tab. 2 contains failed deliveries recorded month-bymonth.

\begin{tabular}{|c|c|c|c|c|c|c|c|c|c|c|c|c|}
\hline \multirow{2}{*}{$\begin{array}{l}\text { Month of } \\
\text { delivery }\end{array}$} & \multicolumn{12}{|c|}{ Month of failed delivery recorded } \\
\hline & 1 & 2 & 3 & 4 & 5 & 6 & 7 & 8 & 9 & 10 & 11 & 12 \\
\hline 1 & & 1 & 2 & 1 & 2 & 1 & 2 & 2 & 1 & 2 & 1 & 1 \\
\hline 2 & & & 1 & 1 & 1 & 2 & 1 & 1 & 2 & 1 & 2 & 1 \\
\hline 3 & & & & 3 & 2 & 1 & 2 & 2 & 2 & 1 & 2 & 2 \\
\hline 4 & & & & & 2 & 3 & 2 & 1 & 1 & 1 & 2 & 2 \\
\hline 5 & & & & & & 3 & 3 & 2 & 1 & 2 & 3 & 1 \\
\hline 6 & & & & & & & 1 & 3 & 2 & 1 & 1 & 1 \\
\hline 7 & & & & & & & & 2 & 3 & 3 & 2 & 2 \\
\hline 8 & & & & & & & & & 3 & 3 & 2 & 1 \\
\hline 9 & & & & & & & & & & 3 & 3 & 3 \\
\hline 10 & & & & & & & & & & & 2 & 3 \\
\hline 11 & & & & & & & & & & & & 2 \\
\hline 12 & & & & & & & & & & & & \\
\hline
\end{tabular}

\subsection{Calculations}

The calculations were made with the use of ReliaSoft Weibull++ software which has a dedicated tool to support the analysis of reliability of deliveries.

Let us consider successful and failed deliveries for the first month of supply. In the first month, 130 deliveries were provided to the customer but 16 failed deliveries appeared as the total of failed deliveries from the first to the eleventh months. It means that 114 deliveries can continue to be provided after five months $\left(S_{11,1}=16\right)$. The total number of failed deliveries at the end of month five of supply is the total of failed deliveries in the first month $\left(F_{1}=F_{1,1}+F_{2,1}\right.$ $+F_{3,1}+F_{4,1},+F_{5,1}+F_{6,1}+F_{7,1}+F_{8,1}+F_{9,1}+F_{10,1}+F_{11}$, $1=1+1+3+2+3+1+2+3+3+2+2=23)$. Following the above scheme, the data on failed deliveries may be converted into life data with failures and suspensions [26]. Failures at 1 month: $F_{1}=23$

Suspensions at 1 month: $S_{11}=S_{11,1}=114$

Failures at 2 months: $F_{2}=F_{1,2}+F_{2,2}+F_{3,2}+F_{4,2}+F_{5,2}+$ $F_{6,2}+F_{7,2}+F_{8,2}+F_{9,2}+F_{10,2}=2+1+2+3+3+3+3+$ $3+3+3=26$

Suspensions at 2 months: $S_{10}=S_{10,2}=142-13=129$

Failures at 3 months: $F_{3}=F_{1,3}+F_{2,3}+F_{3,3}+F_{4,3}+F_{5,3}+$ $F_{6,3}+F_{7,3}+F_{8,3}+F_{9,3}=1+1+1+2+2+2+3+2+3$ $=17$

Suspensions at 3 months: $S_{9}=S_{9,3}=112-17=95$

Failures at 4 months: $F_{4}=F_{1,4}+F_{2,4}+F_{3,4}+F_{4,4}+F_{5,4}+$ $F_{6,4}+F_{7,4}+F_{8,4}=2+2+2+1+1+1+2+1=12$

Suspensions at 4 months: $S_{8}=S_{8,4}=125-14=111$

Failures at 5 months: $F_{5}=F_{1,5}+F_{2,5}+F_{3,5}+F_{4,5}+F_{5,5}+$ $F_{6,5}+F_{7,5}=1+1+2+1+2+1+2=10$

Suspensions at 5 months: $S_{7}=S_{7,5}=120-15=105$

Failures at 6 months: $F_{6}=F_{1,6}+F_{2,6}+F_{3,6}+F_{4,6}+F_{5,6}+$ $F_{6,6}=2+1+2+1+3+1=10$

Suspensions at 6 months: $S_{6}=S_{6,6}=105-9=96$

Failures at 7 months: $F_{7}=F_{1,7}+F_{2,7}+F_{3,7}+F_{4,7}+F_{5,7}=$ $2+2+1+2+1=8$

Suspensions at 7 months: $S_{7}=S_{5,7}=123-12=111$

Failures at 8 months: $F_{8}=F_{1,8}+F_{2,8}+F_{3,8}+F_{4,8}=1+1+$ $2+2=6$

Suspensions at 8 months: $S_{8}=S_{4,8}=118-9=109$

Failures at 9 months: $F_{9}=F_{1,9}+F_{2,9}+F_{3,9}=2+2+2=6$

Suspensions at 9 months: $S_{9}=S_{3,9}=135-9=126$

Failures at 10 months: $F_{10}=F_{1,10}+F_{2,10}=1+1=2$

Suspensions at 10 months: $S_{10}=S_{2,10}=125-5=120$

Failures at 11 months: $F_{11}=F_{1,11}=1=2$

Suspensions at 11 months: $S_{11}=S_{1,11}=102-2=100$

Failures at 12 months: $F_{10}=F_{1,12}=0$

Suspensions at 12 months: $S_{12}=S_{0,12}=110-0=110$ 
The life data obtained from failed deliveries are shown in Tab. 3.

Table 3 Times-to-failure

\begin{tabular}{|c|c|c|}
\hline Number in state & State, $F$ or $S$ & State end time / month \\
\hline 110 & $S$ & 0 \\
\hline 23 & $F$ & 1 \\
\hline 100 & $S$ & 1 \\
\hline 26 & $F$ & 2 \\
\hline 120 & $S$ & 2 \\
\hline 17 & $F$ & 3 \\
\hline 126 & $S$ & 3 \\
\hline 12 & $F$ & 4 \\
\hline 109 & $S$ & 4 \\
\hline 10 & $F$ & 5 \\
\hline 111 & $S$ & 5 \\
\hline 10 & $F$ & 6 \\
\hline 96 & $S$ & 6 \\
\hline 8 & $F$ & 7 \\
\hline 105 & $S$ & 7 \\
\hline 6 & $F$ & 8 \\
\hline 111 & $S$ & 8 \\
\hline 6 & $F$ & 9 \\
\hline 95 & $S$ & 9 \\
\hline 2 & $F$ & 10 \\
\hline 129 & $S$ & 10 \\
\hline 1 & $F$ & 11 \\
\hline 114 & $S$ & 11 \\
\hline & & \\
\hline
\end{tabular}

\section{$4 \quad$ RESULTS AND DISCUSSION}

Based on the time to failure table, the next step is to conduct a goodness-of-fit analysis in order to obtain the most accurate model of reliability of deliveries. During the statistical tests (Chi Square, Kolmogorov-Smirnov) methodology, we selected the 3-parameter Weibull distribution as the most accurate model. The probability density function of 3-parameter Weibull distribution is given as follows:

$f(t)=\frac{\beta}{\eta}\left(\frac{t-\gamma}{\eta}\right)^{\beta-1} \exp \left(-\frac{t-\gamma}{\eta}\right)^{\beta}$, dla $t \geq 0$

where: $\beta$ - shape parameter, $\eta$ - scale parameter, $\gamma$ - location parameter.

Then, using the Maximum Likelihood Estimation the parameters of 3P Weibull distribution were estimated to be: $\beta=0.718544 ; \eta=142.473013$ month, $\gamma=0.505000$. Goodness-of-fit of the 3P Weibull model is shown in Fig. 4. Using the obtained parameters, the selected reliability characteristics may be drawn, such as: reliability of delivery, unreliability of delivery, failure rate of delivery (Figs. 5 to 7, the blue lines). The two-sided confidence bounds (Figs. 4 to 7, the red lines) are taken into account at the level of 0.95 , [15].

In order to calculate the confidence bounds for the characteristics of Weibull distribution we use Fisher Matrix based on the inversed Fisher information matrix. The bounds could be calculated with the use of the given equation:

$$
C B=E(G) \pm z_{a} \sqrt{\operatorname{Var}(G)}, \text { dlat } \geq 0
$$

where: $E(G)$ - is the estimated mean value of the parameter $G, \operatorname{Var}(G)$ - is the variance of the parameter $G, a=1-C L$, where $C L$ is the confidence level, $z_{a}$ - is a standard normal statistic.

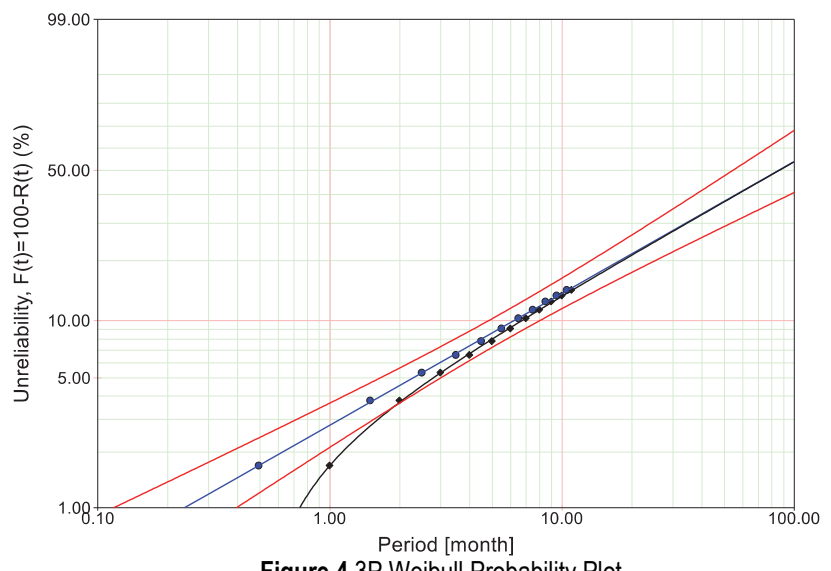

Figure 4 3P Weibull Probability Plo

Taking into account the period of 20 months, the significant changes in the function of the reliability of delivery function as well as in the probability of unsuccessful delivery function may be noticed (Fig. 5 and Fig. 6, respectively). It seems obvious that the longer the logistics service period, the greater the likelihood of warranty returns. Fig. 7 shows the frequency of returns over the time of sales. Confidence intervals are a measure of calculation errors resulting from the limited accuracy of the model used and the amount of data used in the analysis. The possibility of making the errors is greater the greater the period in which deliveries were made.

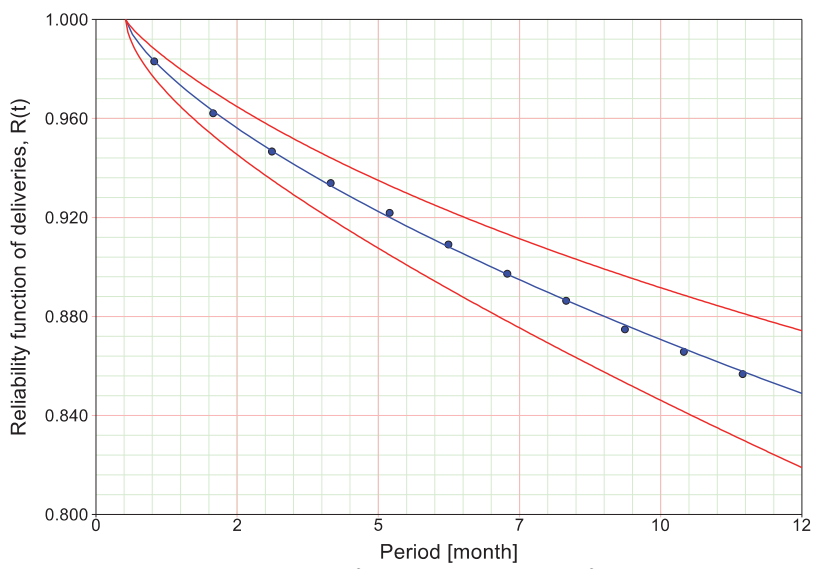

Figure 5 Reliability of deliveries vs. period of time plot

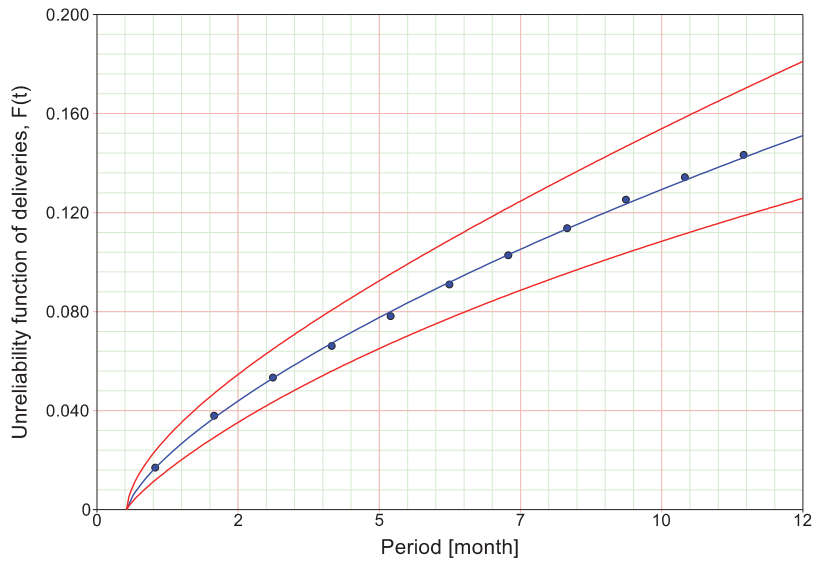

Figure 6 Unreliability of deliveries vs. period of time plot 


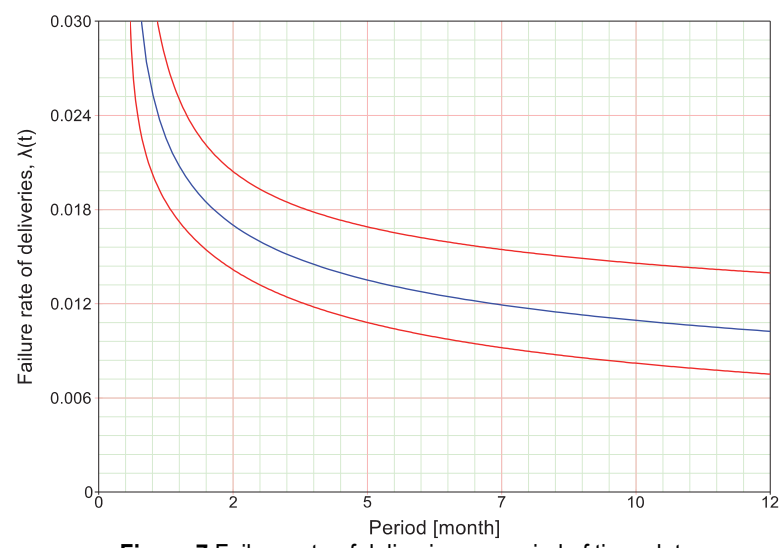

Figure 7 Failure rate of deliveries vs. period of time plot

The benefit of using an approach based on mathematical modelling of warranty returns is the ability to forecast future returns. In this analysis, a forecast has been made for the next six months. Fig. 8 shows a growing trend in expected returns. The upper and lower limits of the confidence interval are marked with red lines.

The following conclusions can be drawn from the calculation results obtained: among the average number of expected returns in month 13,1 delivery was realised in each of 1-8 months, 2 deliveries were realised in each of 912 months. Therefore, the average number of possible returns in month 13 is expected to be 16 . What is more, according to the assumed confidence bounds, there is a probability of 0.95 that the actual return figure will be within the range of 14 to 17 (lower and upper band). By proceeding as described, one can analyse the rest of the Tab. 4.

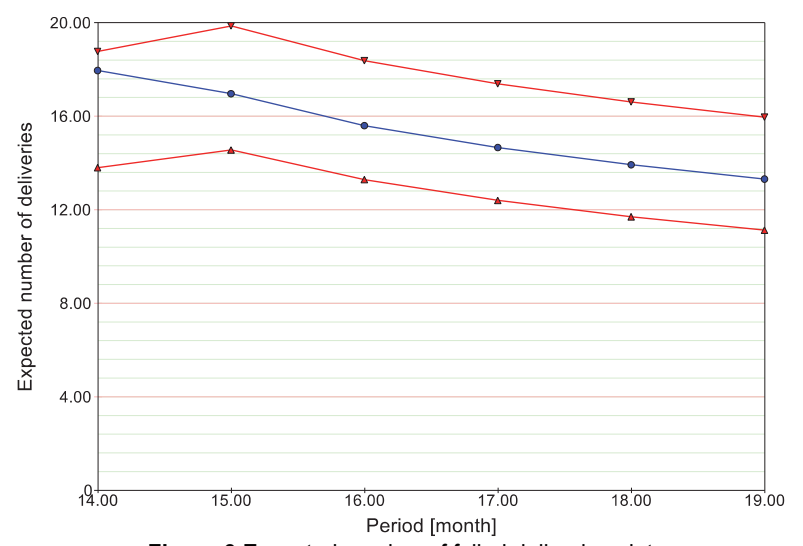

Figure 8 Expected number of failed deliveries plot

Tab. 4 includes the exact values of returns in the selected period.

Table 4 Forecast numbers of failed deliveries in selected months

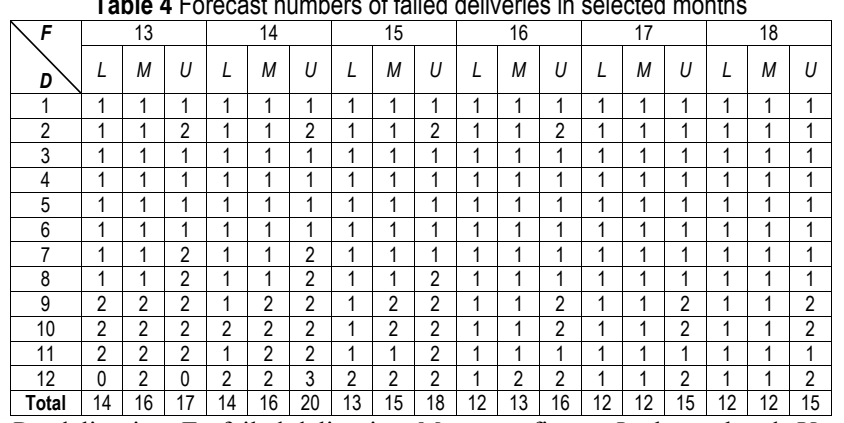

$D$ - deliveries, $F$ - failed deliveries, $M$ - mean figure, $L$ - lower band, $U$ upper band
The presented method of performing the analysis on the example used allows to estimate the number of warranty returns in the following months. This may be one of the first steps on the way to developing some preventive activities to improve reliability of deliveries. The applied method can be used to determine the link between returns and a specific part of delivery.

\section{CONCLUSIONS}

In the following paper the authors discuss the importance of reliability of deliveries as a very important link in the entire supply chain, affecting factors such as the efficiency and competitiveness of enterprises. Conducting research as part of this work was preceded by a thorough analysis of the results of surveys concerning both service providers and recipients. The basis for making a warranty return forecast is historical data, the credibility of which affects the accuracy of the results. The advantage of the approach used is the ability to adapt to other applications related to the occurrence of undesirable events. The scientific approach presented in the following paper also has some limitations. One of them is the inability to take into account the reasons for the appearance of warranty returns in individual periods. In addition, in the case of an extensive data set over a long period of time, the use of this method can be time consuming or may require the use of dedicated software, which involves additional costs for the company. In the scope of future work, the authors see the need to extend the warranty analysis method and introduce a classification of potential reasons for warranty returns in order to carry out a detailed analysis and planning of rapid preventive actions.

\section{REFERENCES}

[1] Aksezer, C. S. (2011). Failure analysis and warranty modelling of used cars. Engineering Failure Analysis, 18, 1520-1526. https://doi.org/10.1016/j.engfailanal.2011.05.009

[2] Gajewska, T. \& Kaczor, G. (2014). Analiza niezawodności dostaw w transporcie chłodniczym. Logistyka, 5, 1-10.

[3] Gajewska, T. \& Grigoroudis, E. (2017). Estimating the performance of the logistics services attributes influencing customer satisfaction in the field of refrigerated transport. International Journal of Shipping and Transport Logistics, 9(5), 540-561. https://doi.org/10.1504/IJSTL.2017.086350

[4] Galkin, A., Dolia, C., \& Davidich, N. (2017). The role of consumers in logistics systems. Transportation Research Procedia, 27, 1187-1194.

[5] Gupta, S.K., De, S., \& Chatterjee, A. (2014). Warranty forecasting from incomplete two-dimensional warranty data. Reliability Engineering \& System Safety, 126, 1-13. https://doi.org/10.1016/j.ress.2014.01.006

[6] Huang, Y-S., Gau, W-Y., \& Ho, J-W. (2015) . Cost analysis of two-dimensional warranty for products with periodic preventive maintenance. Reliability Engineering \& System Safety, 134, 51-58. https://doi.org/10.1016/j.ress.2014.10.014

[7] Jezierski, A. (2005). Multiperspektywistyczne definiowanie jakości procesów logistycznych w dobie konsumenckiej. LogForum, 1(6), 1-6.

[8] Kaczor, G. \& Zając, G. (2012). Analiza niezawodności wtryskiwaczy. Czasopismo techniczne. Mechanika, 109(7M), 327-334.

[9] Kempny, D. (2008). Obstuga logistyczna. Wydawnictwo AE w Katowicach.

[10] Kisperska-Moron, D. (2009). Logistyka. ILiM. 
[11] Lazarević, Ž., Aranđelović, I., \& Kirin, S. (2018). The Reliability of Bucket Wheel Excavator - Review of Random Mechanical Failures. Technical Gazette, 25(4), 1259-1264. https://doi.org/10.17559/TV-20160727170019

[12] Meng, S. M., Liang, G. S., Lin, K., \& Chen, S. Y. (2010). Criteria for services of air cargo logistics providers: How do they relate to client satisfaction? Journal of Air Transport Management, 16(5), 284-286. https://doi.org/10.1016/j.jairtraman.2010.02.003

[13] Nunnaly, J. C. \& Berstein, I. H. (1995). Psychometric Theory (3rd ed.). McGraw-Hill.

[14] Oppenheim, A. N. (2004). Kwestionariusze, wywiady, pomiary postaw. Wydawnictwo Zysk i S-ka, Poznań.

[15] Relia Soft Corporation, Life Data Analysis. Weibull 7++, Tucson AZ USA, (2007)

[16] Romanov, P. (2003). Zarządzanie transportem przedsiębiorstw przemystowych. WSL, Poznań.

[17] Rusell, R. S. \& Taylor B. W. (2011). III, Operation Management. Creating Value Along the Supply Chain. John Wiley and Sons, Inc., 156-188.

[18] Sagan, A. (2004). Badania marketingowe: podstawowe kroki. WSE Kraków.

[19] Su, C. \& Shen, J. (2012). Analysis of extended warranty policies with different repair options. Engineering System Failure Analysis, 25, 49-62. https://doi.org/10.1016/j.engfailanal.2012.04.002

[20] Szkoda, M. (2014). Assessment of reliability, availability and maintainability of rail gauge change systems. Eksploatacja $i$ Niezawodnosc - Maintenance and Reliability, 16(3), 422-432.

[21] Tsoukalas, M. Z. \& Agrafiotis, G. K. (2013). A new replacement warranty policy indexed by the product's correlated failure and usage time. Computers \& Industrial Engineering, 66(2), 203-211. https://doi.org/10.1016/j.cie.2013.07.013

[22] Wang, Y., Liu, Y., Liu, Z., \& Li, X. (2017). On reliability improvement program for second-hand products sold with a two-dimensional warranty. Reliability Engineering \& System Safety, 167, 452-463. https://doi.org/10.1016/j.ress.2017.06.029

[23] Wu, S. (2012). Warranty data analysis: A review. Quality and Reliability Engineering International, 28(8), 795-805. https://doi.org/10.1002/qre.1282

[24] Wu, S., Gitzel, R., \& Turin, S. (2016). On assumptions in optimization of warranty policies. The 9th IMA International Conference on Modelling in Industrial Maintenance and Reliability. 12-14 July, London.

[25] Xie, W., Shen, L., \& Zhong, Y. (2017). Two-dimensional aggregate warranty demand forecasting under sales uncertainty. Quality \& Reliability Engineering, 49, 553-565. https://doi.org/10.1080/24725854.2016.1263769

[26] Transport - logistyka i ustugi. Publiczny transport pasażerski. Definicje, cele i pomiary dotyczace jakości usług. (2004). PNEN 13816: 16.

[27] See http://reliawiki.org/index.php/Warranty_Data_Analysis (accessed 21 May 2012).

\section{Contact information:}

Teresa GAJEWSKA, PhD

(Corresponding author)

Cracow University of Technology,

Faculty of Mechanical Engineering,

Al. Jana Pawla II 37, 31-864 Krakow, Poland

E-mail: teresa.gajewska@pk.edu.pl

\section{Grzegorz KACZOR, PhD}

Cracow University of Technology,

Faculty of Mechanical Engineering,

Al. Jana Pawla II 37, 31-864 Krakow, Poland

E-mail: gkaczor@pk.edu.pl

Maciej SZKODA, PhD, DSc

Cracow University of Technology,

Faculty of Mechanical Engineering,

Al. Jana Pawla II 37, 31-864 Krakow, Poland

E-mail: maciej.szkoda@pk.edu.pl 